IOS Press

\title{
Development of a multiplexed microsatellite set for fingerprinting red raspberry (Rubus idaeus) germplasm and its transferability to other Rubus species
}

\author{
F. Fernández-Fernández*, L. Antanaviciute, C.L. Govan and D.J. Sargent \\ East Malling Research (EMR), Kent, UK
}

Received 18 October 2010; accepted 2 March 2011

\begin{abstract}
This study aimed to develop a standardised and cost effective protocol for fingerprinting red raspberry germplasm using microsatellite (SSR) markers. Twenty SSRs well distributed through the raspberry genome were screened on 16 genetically diverse cultivars to assess polymorphism, allele size range, quality of amplification, ease of scoring, and discriminating power (DF). We selected published SSR markers that were highly informative, consistently easy to score, provided good genome coverage and could be conveniently amplified into two multiplexed reactions. As a proof of concept, the fingerprinting set was used to genotype 37 red raspberry cultivars of various origins and 19 advanced selections from our breeding programme. The multiplexed set amplified consistently the same products originated by single reactions and it reliably discriminated all non-clonal accessions including full-sib genotypes. Furthermore the set was tested on 19 accessions of eight related Rubus species to assess its transferability. Provided control samples are included, this set will permit research groups to share data accurately and easily. The use of DNA fingerprinting to ensure trueness-to-type of clonally propagated horticultural crops is increasingly common and this multiplexed set constitutes a reliable, convenient and economic tool for raspberry genotyping.
\end{abstract}

Keywords: Genotyping, trueness-to-type, SSR, caneberry

\section{Introduction}

Red raspberry (Rubus idaeus L.) belongs, as many other temperate fruit crops, to the Rosaceae family. The Rubus genus comprises several hundreds of species and hybrids of which most of the cultivated types belong to one of the two largest subgenera: Rubus (blackberries) and Idaeobatus (raspberries). The raspberry subgenera are diploid $(2 n=2 x=14)$ and comprise the European red raspberry (R. idaeus L.), the North American red raspberry (R. strigosus Michx.), the black raspberry (R. occidentalis L.) and their hybrid, aptly known as the purple raspberry $(R$. $\times n e g l e c t u s$ Peck), whilst blackberries species vary greatly in ploidy.

Worldwide production of raspberries exceeds 500,000 Mt per year with the Russian Federation, the EU, Serbia and the US as the largest producers [1]. New raspberry cultivars become available every year and the nursery business is thriving and complex. Approximately 1,600 ha are currently dedicated to raspberries in the UK with more than $80 \%$ of production currently being grown under protection. Annual domestic production is around 14,000 $\mathrm{t}$ with a value in the region of $£ 95 \mathrm{M}[2]$.

${ }^{*}$ Corresponding author: F. Fernández-Fernández, East Malling Research (EMR), New Road, East Malling, Kent ME19 6BJ, UK. Tel.: +44 (0)1732 523 739; Fax: +44 (0)1732 849 067; E-mail: felicidad.fernandez@emr.ac.uk. 
Raspberry cultivars are propagated clonally from their roots or in vitro using meristem cultures and are commercialised as small rooted plants or as dormant canes carrying the root system. Propagation stocks can go through several rounds of vegetative multiplication during which the absence of fruit makes morphological verification very difficult and errors can be extremely costly. Thus, ensuring trueness-to-type of the material during this process as well as at the point of sale is critical. Furthermore, reliable DNA fingerprinting is essential to protect breeders' rights, police illegal fruit sales and should be routinely incorporated to propagation protocols to ensure cultivar integrity.

Early attempts to characterise raspberry germplasm using molecular markers concentrated in non sequence-specific markers such as RAPDs and AFLPs. RAPDs have been used to determine the relationships within and between Rubus species [3, 4] and for cultivar identification [5]. Likewise, AFLPs have been employed in the assessment of genetic diversity in Rubus [6]. However, in recent years, due to their well documented advantages for diversity studies and linkage map construction, SSRs have become the markers of choice for genetic characterisation of rosaceous species including apple [7], pear [8], cherry [9], peach [10] and strawberry [11]. Caneberries are no exception; SSRs have been developed from a number of different Rubus species [12-16] and recently EST-SSRs have been developed in raspberry and blackberry [17, 18]. Additionally, some studies have tried to determine their usefulness for genetic studies in raspberry and blackberry $[3,16]$.

Despite their advantages over other molecular markers, reproducible and cost-effective SSR fingerprinting requires a careful choice of markers. Ideally a good fingerprinting set would consist of highly polymorphic markers that are distributed throughout the genome and that display robust amplification profiles (low tendency to A-additions, no wavering of large fragments etc.). Such sets have been proposed for a number of rosaceous crops such as strawberry [11], cherry [9] and pear [19]. Additionally, SSR markers can often be combined in multiplexed reactions, in particular when using fluorescently labeled primers, and/or different reactions can be pooled together for electrophoresis thus saving time and money [20]. Ideally the markers selected for a core fingerprinting set should be suitable for multiplexed PCR amplification allowing high-through put and economical genotyping [11, 19].

The purpose this investigation was to use available SSR markers for the development of a robust and cost-effective multiplexed genotyping set for the accurate fingerprinting and thus reliable identification of red raspberry cultivars and breeding lines.

\section{Materials and methods}

\subsection{Plant material and DNA extraction}

Sixteen red raspberry cultivars from a range of different origins and including both primocane and floricane fruiting types were chosen to optimise the SSR set, namely 'Autumn Bliss', 'Autumn Treasure', 'Cascade Delight', 'Cowichan', 'Grushovka Leningradskaya', 'Glen Ample', 'Glen Rosa', 'Haida', 'Heritage', 'Himbotop', 'Latham', 'Malling Jewel', 'Malling Leo', 'Octavia', 'Rubaca' and 'Tulameen'. An additional set of 21 cultivars and 19 advanced selections from EMR's breeding programme (Table 1) were then analysed with the optimised set. Finally, four black raspberry cultivars ('Cumberland', 'Haut', 'Jewel' and 'MacBlack'); six blackberry cultivars ('Arapaho', 'Aurora', 'Black Satin', 'Darrow', 'Kotata' and 'Loch Ness'); four hybrid berries ('Logan Thornless', 'Marionberry', 'Sunberry' and 'Tayberry') and five accessions of related species, namely $R$. coreanus, $R$. crataegifolius, $R$. odoratus, $R$. spectabilis and $R$. strigosus, were also analysed with the optimised set to assess its transferability. All genotypes are maintained as part of the field or pot Rubus germplasm collection at East Malling Research (EMR). To determine both the range of alleles and the ability of the fingerprinting set to distinguish closely related material, we included primocane and floricane-fruiting cultivars from diverse origins as well as interrelated genotypes. DNA was extracted using the DNeasy Plant minikit (Qiagen GmbH, Germany) according to the manufacturer's protocol. DNA was re-suspended in $200 \mu \mathrm{l}$ AE buffer (Qiagen $\mathrm{GmbH}$, Germany) and was diluted 1:200 for use in PCR.

\subsection{Marker selections, PCR conditions and product detection and scoring}

Based on previous experience and reported marker information, a total of 20 SSR markers previously mapped in raspberry $[16,17]$ were tested in 16 genetically-diverse red raspberry cultivars to assess polymorphism, quality of 
Table 1

Parentage and/or origin of the Rubus genotypes (by species) analysed in this study as well as their bearing type - where PF = primocane fruiting and $\mathrm{SF}=$ floricane fruiting - and cultivar year of release. All accessions are diploid $(2 n=2 x=14)$ unless stated

\begin{tabular}{|c|c|c|}
\hline Genotype & Parentage or accession & Type (date) \\
\hline \multicolumn{3}{|l|}{ Red raspberry selections } \\
\hline$\overline{\text { EM6564/87 }}$ & EM3655/47 × Kitsilano & $\mathrm{SF}$ \\
\hline EM6631/64 ${ }^{1}$ & EM6429/90 $\times$ Tulameen & $\mathrm{SF}$ \\
\hline EM6685/2 1 & EM6429/6 × Malahat & $\mathrm{SF}$ \\
\hline EM6686/25 ${ }^{1}$ & Glen Ample $\times$ EM6305/12 & $\mathrm{SF}$ \\
\hline EM6686/26 1 & Glen Ample $\times$ EM6305/12 & $\mathrm{SF}$ \\
\hline EM6710/1321 & EM6481/17 × EM6535/1 & $\mathrm{PF}$ \\
\hline EM6727/26 & EM6482/112 × EM6442/155 & $\mathrm{PF}$ \\
\hline EM6727/63 1 & EM6482/112 × EM6442/155 & $\mathrm{PF}$ \\
\hline EM6732/96 ${ }^{1}$ & EM6413/59 × EM6488/58 & $\mathrm{SF}$ \\
\hline EM6739/75 ${ }^{1}$ & Glen Ample $\times$ EM6399/84 & $\mathrm{SF}$ \\
\hline EM6741/89 ${ }^{1}$ & SCRI9059C1 $\times($ Himboqueen $\times$ Julia $)$ & $\mathrm{SF}$ \\
\hline EM6761/55 ${ }^{1}$ & $($ Himboqueen $\times$ Julia $) \times($ EM5928/22 $\times$ Glen Ample $)$ & $\mathrm{SF}$ \\
\hline EM6769/75 ${ }^{1}$ & Polana $\times$ EM6531/62 & $\mathrm{PF}$ \\
\hline EM6780/81 ${ }^{1}$ & Joan Squire $\times$ EM6592/11 & $\mathrm{PF}$ \\
\hline EM6803/185 & Octavia $\times($ EM3655/47 $\times$ Kitsilano $)$ & SF \\
\hline EM6804/122 1 & Tulameen $\times$ Octavia & $\mathrm{SF}$ \\
\hline EM6804/94 1 & Tulameen $\times$ Octavia & $\mathrm{SF}$ \\
\hline EM6881/102 1 & EM6727/35 × Polka & $\mathrm{PF}$ \\
\hline EM6886/91 ${ }^{1}$ & Maravilla open pollination & $\mathrm{PF}$ \\
\hline \multicolumn{3}{|l|}{ Red raspberry cultivars } \\
\hline$\overline{\text { Autumn Bliss }^{2}}$ & Derivative of Landmark, M. Promise and $R$. articus & PF (1983) \\
\hline Autumn Treasure ${ }^{2}$ & EM6304/36 × EM6330/96 & PF (2005) \\
\hline Brice $^{3}$ & J. Squire $\times(93119 / 4 \times($ Terri-Louise $\times$ J.Squire $))$ & PF (2005) \\
\hline Cascade Delight ${ }^{4}$ & Chilliwack $\times$ WSU994 (= derv. of Meeker and Haida) & SF (2003) \\
\hline Cowichan ${ }^{5}$ & Newburg $\times$ Qualicum & SF (2001) \\
\hline Erika $^{6}$ & Tulameen $\times$ Autumn Bliss & PF (2007) \\
\hline Esquimalt $^{5}$ & Comox $\times$ Glen Ample & SF (2003) \\
\hline Grushovka Leningradskaya $^{7}$ & Unknown & SF (?) \\
\hline Glen Ample ${ }^{8}$ & Derivative of G. Prosen, Meeker, Preussen, M. Promise & SF (1996) \\
\hline Glen Doll ${ }^{8}$ & Glen Rosa $\times$ SCRI $8605 C 2$ & SF (2006) \\
\hline Glen Fyne ${ }^{8}$ & SCRI8631D1 × SCRI8605C2 & SF (1992) \\
\hline Glen Lyon ${ }^{8}$ & $($ SCRI6820/35 $\times$ Haida $) \times($ SCRI703/36 $\times$ G. Prosen $)$ & SF (1994) \\
\hline Glen Rosa ${ }^{8}$ & Derivative of G. Prosen, Meeker, Preussen, M. Promise & SF (1994) \\
\hline Haida $^{5}$ & Malling Promise $\times$ Creston & SF (1972) \\
\hline Heritage $^{9}$ & (Milton $\times$ Cuthbert $) \times$ Durham & PF (1969) \\
\hline Himbotop $^{10}$ & Autumn Bliss $\times$ Himboqueen & PF (2008) \\
\hline Ivars $^{7}$ & Unknown & $\mathrm{SF}(?)$ \\
\hline Joan Squire ${ }^{3}$ & $(\mathrm{~J}$. Squire $\times$ J. Irene $) \times($ A. Bliss $\times$ R.spectabilis $)$ & PF (1994) \\
\hline Kiwigold & Yellow sport of Heritage & PF (1997) \\
\hline Latham $^{11}$ & King $\times$ Loudon & SF (1920) \\
\hline Malahat $^{5}$ & Meeker $\times$ BC7853/116 & SF (1996) \\
\hline Malling Hestia ${ }^{2}$ & EM3689/5 × EM3655/48 & SF (2006) \\
\hline Malling Jewel $^{2}$ & Derivative of Preussen, Lloyd George and Pyne's Royal & SF (1980) \\
\hline Malling Juno ${ }^{2}$ & EM6166/79 × EM6304/36 & SF (2005) \\
\hline Malling Leo ${ }^{2}$ & EM791/45 × EM765/30 & $\mathrm{SF}(1975)$ \\
\hline
\end{tabular}


Table 1

(Continued)

\begin{tabular}{|c|c|c|}
\hline Genotype & Parentage or accession & Type (date) \\
\hline Malling Minerva $^{2}$ & EM5030/3 × SCRI7269/67 & SF (2005) \\
\hline Marcela $^{3}$ & Joan Squire $\times$ Autumn Bliss & $\mathrm{PF}(2005)$ \\
\hline Nagrada $^{7}$ & Kolkhoznitsa $\times$ Lloyd George & SF (?) \\
\hline Octavia $^{2}$ & Malling Hestia $\times$ Glen Ample & SF (2002) \\
\hline Polana ${ }^{12}$ & Heritage $\times$ Zeva Herbsternte & $\mathrm{PF}(1991)$ \\
\hline Polka $^{12}$ & P89141(=Autumn Bliss derivative) open pollination & $\mathrm{PF}(2001)$ \\
\hline Rannaya Sladkaya $^{7}$ & Red Antwerp derivative & $\mathrm{SF}(?)$ \\
\hline Rubaca $^{13}$ & Rucanta $\times$ Latham & SF (1993) \\
\hline Rutrago $^{13}$ & Klon4a $\times$ Tragilo & SF (1980) \\
\hline Sugana $^{6}$ & Tulameen $\times$ Autumn Bliss & PF (2008) \\
\hline Tulameen $^{5}$ & Nootka $\times$ Glen Prosen & SF (1989) \\
\hline Valentina $^{2}$ & EM6225/11 × EM5588/81 & SF (2005) \\
\hline \multicolumn{3}{|l|}{ Black raspberry cultivars } \\
\hline Cumberland $^{14}$ & Gregg selfed & SF (1896) \\
\hline Haut $^{15}$ & $($ Manteo selfed $) \times($ Bristol selfed $)$ & SF (1980) \\
\hline Jewel $^{9}$ & NY.29773 $\times$ Dundee & SF (1973) \\
\hline MacBlack $^{16}$ & unknown & \\
\hline \multicolumn{3}{|l|}{ Blackberry cultivars } \\
\hline $\operatorname{Arapaho}^{17}(4 \mathrm{x})$ & $($ Ark. $550 \times$ Cherokee $) \times$ Ark. 883 & SF (1993) \\
\hline Aurora $^{18}(8 \mathrm{x})$ & ORUS616 $\times$ ORUS73 & SF (1961) \\
\hline Black Satin ${ }^{19}(4 x)$ & (US $1482 \times$ Darrow) $\times$ Thornfree & SF (1974) \\
\hline Darrow $^{9}(4 x)$ & $($ Eldorado $\times$ Brewer $) \times$ Hedrick & SF (1958) \\
\hline \multicolumn{3}{|l|}{ Hybrid-berry cultivars } \\
\hline$\overline{\text { Logan Thornless }^{20}(6 x)}$ & Thornless mutation of Loganberry on unknown origen & SF (1933) \\
\hline Marionberry ${ }^{18}(6 x)$ & Chehalem $(6 x) \times$ Olallie $(6 x)$ & SF (ca.1950) \\
\hline Sunberry $^{2}(6 x)$ & R.ursinus $(8 \mathrm{x}) \times($ M. Jewel $(4 \mathrm{x})$ selfed $)$ & SF (1967) \\
\hline Tayberry $^{8}(6 x)$ & Aurora $(8 x) \times \operatorname{SCRI} 626 / 67(4 x)$ & SF (1979) \\
\hline \multicolumn{3}{|c|}{ Accessions from other Rubus spp } \\
\hline R. coreanus & L646 & SF \\
\hline R. crataegifolius & L1032 & SF \\
\hline R. odoratus & L992 & SF \\
\hline R. spectabilis & L544 & SF \\
\hline R. strigosus & L518 & SF \\
\hline
\end{tabular}

${ }^{1}$ East Malling Research breeding line (UK); ${ }^{2}$ Bred at East Malling Research (UK); ${ }^{3}$ Bred by Medway Fruits / ReDeva (UK); ${ }^{4}$ Bred at Washington State University (USA); ${ }^{5}$ Bred at Agriculture and Agri-Food Canada (BC - Canada); ${ }^{6}$ Bred by Agricultural Research Council (CRA) (Italy); ${ }^{7}$ Bred or selected in research institutes of the former USSR; ${ }^{8}$ Bred at Scottish Crop Research Institute (UK); ${ }^{9}$ Bred in Geneva, New York (USA); ${ }^{10}$ Bred in Switzerland; ${ }^{11}$ Bred in Minnesota (USA); ${ }^{12}$ Bred at the Research Institute of Pomology and Floriculture (Poland); ${ }^{13}$ Bred at the Max Planck Institute (Germany); ${ }^{14}$ Bred or selected in Pennsylvania (USA); ${ }^{15}$ Bred or selected in Maryland (USA); ${ }^{16}$ Probably bred or selected by E. Lowden in Ontario (Canada); ${ }^{17}$ Bred in Arkansas (USA); ${ }^{18}$ Bred in Oregon (USA); ${ }^{19}$ Bred or selected by J.N. Hull in Illinois (USA); ${ }^{20}$ Bred or selected by G. Bauer in California (USA). 
amplification and ease of scoring. This group included two to four markers from each of the seven raspberry linkage groups (Table 2) to ensure good genome coverage.

Initial PCRs were performed individually for each primer pair in $12.5 \mu \mathrm{l}$ reactions containing $0.2 \mu \mathrm{M}$ forward primer, $0.2 \mu \mathrm{M}$ reverse primer labelled with fluorescent dyes 6-FAM, VIC, NED or PET (Applied Biosystems), $0.2 \mathrm{mM}$ of each dNTP, $1.5 \mathrm{mM} \mathrm{MgCl}_{2}$ and $0.25 \mathrm{U}_{\text {of Amplitaq }}{ }^{\circledR}$ polymerase in GeneAmp ${ }^{\circledR}$ buffer of $10 \mathrm{mM}$ Tris-HCl ( $\mathrm{pH} 8.3$ ) and $50 \mathrm{mM} \mathrm{KCl}$ (all reagents from Applied Biosystems). The PCR cycling regime consisted of an initial 3 min denaturation step at $94^{\circ} \mathrm{C}$, ten touch-down cycles comprising a $30 \mathrm{~s}$ denaturation at $94^{\circ} \mathrm{C}$ followed by $90 \mathrm{~s}$ of annealing starting at $60^{\circ} \mathrm{C}$ and decreasing, $1^{\circ} \mathrm{C}$ per cycle, down to $50^{\circ} \mathrm{C}$ and $60 \mathrm{~s}$ of extension at $72^{\circ} \mathrm{C}$. Subsequently, 25 more identical cycles were conducted with and annealing temperature of $50^{\circ} \mathrm{C}$ followed by a final 30 min extension step at $60^{\circ} \mathrm{C}$. PCR products were loaded undiluted to be separated by electrophoresis on an ABI 3100 prism genetic analyser (Applied Biosystems). Data generated were then collected and analysed using the GENESCAN and GENOTYPER (Applied Biosystems) software and checked visually by at least two researchers. Failed reactions were repeated taking care to include samples that worked in the original screen to ensure consistency of scoring.

\subsection{Multiplexed PCR reactions}

Eight SSRs were chosen as the core fingerprinting set for red raspberry taking into account polymorphism, linkage group and ease of scoring in 16 genotypes. These eight markers were grouped into two separate multiplexed reactions, MP_A and MP_B (Table 2), and used to screen all genotypes. Each multiplex included equimolar amounts of four markers each one labelled with a different fluorescent molecule (6-FAM, VIC, NED or PET). Multiplexed reactions were carried out in 13- $\mu$ l reactions using Type-it ${ }^{\mathrm{TM}}$ Microsatellite PCR kit (Qiagen) according to the manufacturer instructions and thermal cycling as above. Products from multiplexed reactions were diluted 1:50, 1:100 and 1:200 prior to analysis and separated by electrophoresis on an ABI 3100 prism genetic analyser (Applied Biosystems). Data generated were then collected and analysed using the GENESCAN and GENOTYPER (Applied Biosystems) software and checked visually by at least two researchers. Amplicons were compared to those produced by the same markers on single PCR and failed reactions were repeated alongside previously scored genotypes to ensure consistency of scoring.

\subsection{Data analysis}

Usefulness of the markers was evaluated based on amplification of the 16 test cultivars. Number of alleles and number of unique genotypes per marker were noted and discrimination power was calculated as $D P=1-\sum P_{i}^{2}$ where $P_{i}$ is the frequency of the $i^{\text {th }}$ genotype (Table 2).

A data matrix was created from the scored peaks for all 56 Rubus accessions amplified with the eight selected primer pairs. Data were analysed following the methods described by Marchese et al. [21]. The peaks were scored as present (1) or absent (0) for each accession and then all data were combined into a single matrix for clustering analysis with unweighted pair group method with arithmetic mean (UPGMA) using PAUP (Phylogenetic Analysis Using Parsimony) software [22], from which a phenogram showing phenetic similarity was then constructed with TREEVIEW [23]. Phylogenetic bootstrapping was performed using 10,000 replicates to establish support for relationships inferred from the UPGMA analysis.

\section{Results}

\subsection{Single PCR performance and marker selection}

All 20 primers amplified one or two alleles in each of the 16 test genotypes. However Rub120a, which was seemingly homozygous in many genotypes, could not achieve amplification for three samples even after various attempts, thus suggesting the presence of 'null' alleles (data not shown).

Marker polymorphism and discrimination power (DP) varied considerably between primer pairs. RhM001 was found to be the least useful having revealed only two different alleles and two unique genotypes (DF $=0.49)$ whereas 
Table 2

SSR markers tested detailing source for primer sequence, raspberry linkage group (LG), number of alleles amplified (N(16)), number of unique genotypes (UG) and discrimination power (DP) in the 16 cultivar used for preliminary evaluation as well as multiplex reaction and dye; total number of alleles and size range allele in 16 and 56 red raspberry genotypes (multiplexed SSR markers, only)

\begin{tabular}{|c|c|c|c|c|c|c|c|c|}
\hline \multirow[t]{2}{*}{ Marker } & \multirow[t]{2}{*}{ LG } & \multirow[t]{2}{*}{$\mathrm{N}(16)$} & \multirow[t]{2}{*}{ UG } & \multirow[t]{2}{*}{$\mathrm{DP}^{1}$} & \multirow[t]{2}{*}{ Multiplex (Dye) } & \multirow[t]{2}{*}{$\mathrm{N}$} & \multicolumn{2}{|c|}{ Range } \\
\hline & & & & & & & 16 & 56 \\
\hline Rubus $285 \mathrm{a}^{2}$ & 1 & 9 & 14 & 0.92 & MP_B (NED) & 11 & $169-193$ & $163-193$ \\
\hline Rubus $124 \mathrm{a}^{2}$ & 1 & 4 & 6 & 0.69 & $\mathrm{n} / \mathrm{a}$ & $\mathrm{n} / \mathrm{a}$ & $143-152$ & $\mathrm{n} / \mathrm{a}$ \\
\hline Rubus $270 a^{2}$ & 2 & 8 & 10 & 0.84 & MP_A (NED) & 11 & $156-209$ & $156-209$ \\
\hline $\mathrm{RhM}_{00} 3^{3}$ & 2 & 6 & 9 & 0.83 & MP_B (VIC) & 9 & $196-214$ & $182-214$ \\
\hline RubruitC $1^{2}$ & 2 & 3 & 4 & 0.73 & $\mathrm{n} / \mathrm{a}$ & $\mathrm{n} / \mathrm{a}$ & $151-161$ & $\mathrm{n} / \mathrm{a}$ \\
\hline RhM001 ${ }^{3}$ & 2 & 2 & 2 & 0.49 & $\mathrm{n} / \mathrm{a}$ & $\mathrm{n} / \mathrm{a}$ & $235-237$ & $\mathrm{n} / \mathrm{a}$ \\
\hline Rubus $223 a^{4}$ & 3 & 7 & 10 & 0.86 & MP_A (VIC) & 10 & $135-172$ & $135-172$ \\
\hline Rub120a $a^{5}$ & 3 & 4 & 5 & 0.66 & $\mathrm{n} / \mathrm{a}$ & $\mathrm{n} / \mathrm{a}$ & $180-188$ & $\mathrm{n} / \mathrm{a}$ \\
\hline Rubus $16 \mathrm{a}^{2}$ & 3 & 6 & 5 & 0.61 & $\mathrm{n} / \mathrm{a}$ & $\mathrm{n} / \mathrm{a}$ & $132-167$ & $\mathrm{n} / \mathrm{a}$ \\
\hline Rubus $110 a^{2}$ & 4 & 9 & 12 & 0.88 & $\mathrm{n} / \mathrm{a}$ & $\mathrm{n} / \mathrm{a}$ & $143-188$ & $\mathrm{n} / \mathrm{a}$ \\
\hline Rubus57a ${ }^{2}$ & 4 & 7 & 9 & 0.86 & $\mathrm{n} / \mathrm{a}$ & $\mathrm{n} / \mathrm{a}$ & $163-194$ & $\mathrm{n} / \mathrm{a}$ \\
\hline Rubus $275 \mathrm{a}^{2}$ & 5 & 12 & 14 & 0.92 & MP_A (PET) & 16 & $116-184$ & 114-186 \\
\hline Rubus $105 b^{2}$ & 5 & 7 & 10 & 0.88 & $\mathrm{n} / \mathrm{a}$ & $\mathrm{n} / \mathrm{a}$ & $160-195$ & $\mathrm{n} / \mathrm{a}$ \\
\hline RiM019 3 & 5 & 9 & 9 & 0.86 & MP_B (PET) & 12 & $167-220$ & $167-220$ \\
\hline Rub5 $a^{5}$ & 5 & 4 & 5 & 0.76 & $\mathrm{n} / \mathrm{a}$ & $\mathrm{n} / \mathrm{a}$ & $154-159$ & $\mathrm{n} / \mathrm{a}$ \\
\hline Rubus $123 \mathrm{a}^{2}$ & 6 & 10 & 11 & 0.85 & MP_A (6-FAM) & 15 & $142-183$ & $135-204$ \\
\hline RiM036 3 & 6 & 3 & 5 & 0.70 & $\mathrm{n} / \mathrm{a}$ & $\mathrm{n} / \mathrm{a}$ & $297-314$ & $\mathrm{n} / \mathrm{a}$ \\
\hline Rubleaf $102^{2}$ & 6 & 3 & 4 & 0.68 & $\mathrm{n} / \mathrm{a}$ & $\mathrm{n} / \mathrm{a}$ & $221-234$ & $\mathrm{n} / \mathrm{a}$ \\
\hline RhM011 3 & 7 & 11 & 12 & 0.88 & MP_B (6-FAM) & 13 & $266-316$ & $266-316$ \\
\hline Rub265a $a^{5}$ & 7 & 6 & 8 & 0.80 & $\mathrm{n} / \mathrm{a}$ & $\mathrm{n} / \mathrm{a}$ & $132-154$ & $\mathrm{n} / \mathrm{a}$ \\
\hline
\end{tabular}

${ }^{1} D P=1-\sum P_{i}^{2}$ where $P_{i}$ is the frequency of the $i^{t h}$ genotype; ${ }^{2}$ Published by Graham et al. $2004 ;{ }^{3}$ Published by Castillo $e t$ al. $2010 ;{ }^{4}$ Published by Graham et al. 2002; ${ }^{5}$ Published by Graham et al. 2006.

Rubus275a and Rubus285a were the most informative amplifying 12 and 9 different alleles respectively; both revealed 14 unique genotypes each $(\mathrm{DF}=0.92)$. Similarly, the quality and consistency of amplification and the ease of scoring also varied greatly among the markers. Markers Rubus57a and Rub5a presented series of three or more consecutive alleles in 1-bp steps that made consistent scoring difficult. Rubus110a and Rub265a amplified products with pronounced stuttering and/or inconsistent non-templated nucleotide addition, making allele size assignation complicated. These were discarded from the core fingerprinting set regardless of their polymorphism. The best overall primer from each linkage group was chosen with the exception of LG4 for which neither of the SSRs tested was satisfactory. Other markers from this linkage group had previously been evaluated for fingerprinting (data not shown) and found to be equally unsuitable. Therefore two additional markers from linkage groups 2 and 5 were chosen to make up the set of eight.

\subsection{Multiplexed PCRs and genotype analysis}

The amplification from multiplexed reactions with the SSR Type-it ${ }^{\mathrm{TM}}$ Microsatellite PCR kit (Qiagen) was consistent with previous scores for single reactions but the product yield was very high causing requiring dilution prior to electrophoresis to allow accurate scoring; a 1:100 dilution was the most suitable.

Although the number of alleles detected for each of the eight selected SSR markers increased when we analysed all 56 individuals, the allele range did not varied substantially (Table 2), suggesting that the 16 genotypes chosen for the preliminary test were satisfactorily representative. 
The similarity of the fingerprints revealed by the multiplexed set for each accession is shown in the phenogram (Fig. 1) and two clusters of genotypes related by known pedigree information have been highlighted. However, the level of bootstrap support for these clusters was below the $75 \%$ cut-off value to be considered are statistically significant. From known pedigree information, supported by their position on the phenogram, six genetically-diverse and commonly-available raspberry cultivars were proposed for the harmonizing of scoring across different future studies; allele sizes revealed by MP_A and MP_B on these genotypes are provided (Table 3).

\subsection{Transferability of the fingerprinting set to other Rubus species}

The set produced good amplification in blackberry and black raspberry accessions (Table 3). As expected on account of their ploidy levels, all markers amplified more than two alleles from the majority of blackberry and hybrid berry genotypes. Only two markers failed to amplify every accession of these crops (Rubus223a did not generate any products in three blackberries and nor did RiM019 that also failed to amplify two black raspberries), nonetheless the set fully discriminated all the cultivars tested. Hybrid berries proved less polymorphic and, despite excellent amplification, we could not distinguish between 'Tayberry' and 'Sunberry'. Most markers in the set also amplified successfully the majority of other Rubus accessions (Table 3).

\section{Discussion}

SSR markers are abundant, co-dominant and easily transferable, allowing for the same locus to be analysed reliably and compared across a wide range of germplasm. After the initial investment in their development, SSRs are inexpensive and straight-forward to use and several markers can be multiplexed in the same reaction to further decrease genotyping costs [20].

Sets of multiplexed SSRs have been proposed for high-through put genotyping in other fruit crops such as strawberry [11] and pear [19]. Previous studies in Rubus have concentrated in determining the usefulness of particular sets of markers for mapping [3, 13, 14]. Castillo et al. presented a set of SSR markers derived from blackberry and red raspberry genomic DNA and evaluated their usefulness for fingerprinting a range of cultivars of both crops [16]. However they presented no multiplexed set and no set of harmonizing genotypes was suggested. We are not aware of any convenient and/or widely accepted set of SSRs for raspberry fingerprinting.

In this investigation, we report a fingerprinting set for red raspberry comprising eight SSR markers multiplexed into two PCR reactions that we have shown to be highly discriminating in a wide range of red raspberry genotypes. Although no individual SSR could differentiate all non-clonal genotypes, each of the two multiplexes could discriminate them with two exceptions (MP_A could not distinguish between 'Joan Squire' and 'Brice' and MP_B could not distinguish between 'Malling Minerva' and 'EM6727/63'). When both multiplexes were combined, the resulting fingerprinting set satisfactorily discriminated between even closely related genotypes; parents and their off-spring as in the case of 'Tulameen' $\times$ 'Autumn Bliss' seedlings 'Erika' and 'Sugana' as well as between siblings (EM6727/26 and EM6727/63; EM6686/25 and EM6686/26; EM6804/94 and EM6804/122; 'Glen Ample' and 'Glen Rosa'; 'Erika' and 'Sugana') whilst producing consistent amplification for clonal variants ('Heritage' and its sport, 'Kiwigold') and for the same genotypes across different runs. The markers selected in this study remained reliable and produced reproducible results in multiplexed reactions allowing substantial savings in labour and consumables alike.

Red raspberry cultivars are, for the most part, complex hybrids derived from a relatively small genetic pool; a few founding clones of $R$. idaeus (European red raspberry) and $R$. strigosus (North-American red raspberry) variously inter-crossed through many generations form the background of most modern cultivars. Closely related species such as $R$. occidentalis, $R$. spectabilis and $R$. crataegifolius were introduced as donors of particular traits (e.g. pest resistance or fruit quality attributes). As a result, and not surprisingly, genetic distances between the genotypes included in this study are small. Nonetheless some groupings related to pedigree can be observed in the phenogram (Fig. 1). Group ' $A$ ' is almost entirely composed of cultivars from the Scottish raspberry breeding programme at SCRI ('Glen' series) or cultivars and selections partly derived from their germplasm (e.g. 'Tulameen', and 'EM6732/96'). On the other hand Octavia ('Glen Ample' derivative), appears to group more closely to its other progenitor ('Malling 


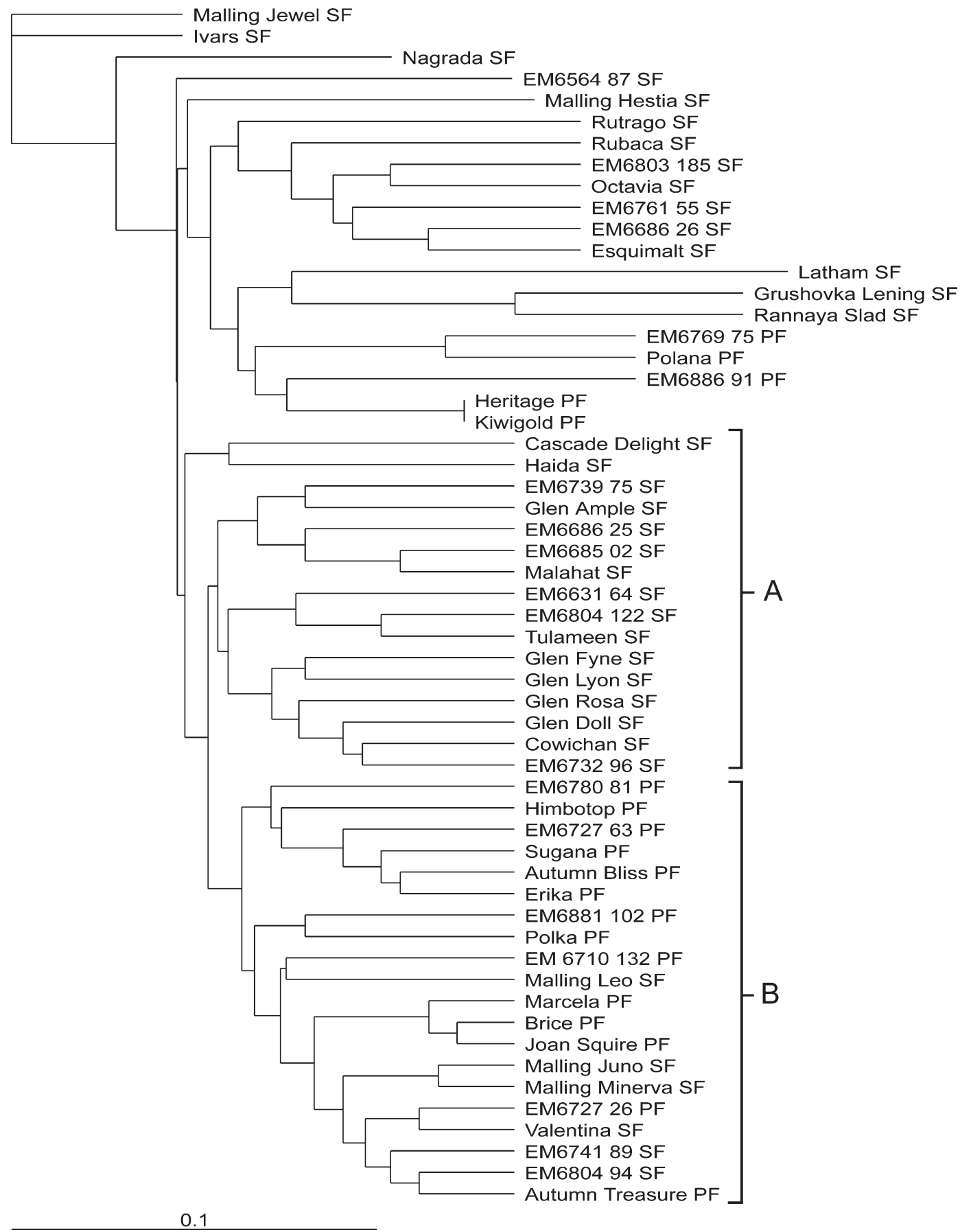

Fig. 1. A UPGMA phenogram showing similarities amongst 56 red raspberry genotypes (37 cultivars and 19 numbered selections) based on genotype data produced by eight SSR markers amplified in two multiplexes. 
Table 3

Standardised allele sizes of a set of six red raspberry cultivars for all eight SSR markers as multiplexed in the fingerprinting set (MP_A and MP_B) and their transferability to other Rubus species

\begin{tabular}{|c|c|c|c|c|c|c|c|c|c|c|c|c|c|c|c|c|}
\hline \multirow[t]{2}{*}{ MP } & \multirow{2}{*}{$\begin{array}{l}\text { SSR } \\
\text { Marker }\end{array}$} & \multicolumn{6}{|c|}{ Proposed Red raspberry control cultivars } & \multicolumn{9}{|c|}{ Transferability to other Rubus species* } \\
\hline & & $\begin{array}{c}\text { Autumn } \\
\text { Bliss }\end{array}$ & $\begin{array}{c}\text { Glen } \\
\text { Ample }\end{array}$ & Heritage & Latham & $\begin{array}{c}\text { Malling } \\
\text { Jewel }\end{array}$ & Tulameen & $\begin{array}{c}\text { Size } \\
\text { range }\end{array}$ & $\mathrm{BR}^{1}$ & $\mathrm{BB}^{2}$ & $\mathrm{HB}^{3}$ & $\mathrm{COR}^{4}$ & $\mathrm{CRA}^{5}$ & $\mathrm{ODR}^{6}$ & $\mathrm{SPE}^{7}$ & $\mathrm{STR}^{8}$ \\
\hline A & Rubus123a & $142 / 183$ & $142 / 146$ & 146 & $150 / 169$ & 148 & $142 / 148$ & $132-252$ & $3(4)$ & $9(6)$ & $7(4)$ & $2(1)$ & $2(1)$ & $1(1)$ & - & $2(1)$ \\
\hline A & Rubus223a & $148 / 152$ & 150 & $143 / 150$ & $134 / 143$ & 148 & 148 & $125-170$ & $2(4)$ & $6(3)$ & $4(4)$ & $2(1)$ & - & - & - & $2(1)$ \\
\hline A & Rubus270a & 156 & 186 & $181 / 207$ & $181 / 209$ & $156 / 188$ & 156 & $136-188$ & $4(4)$ & $10(6)$ & $7(4)$ & $2(1)$ & $2(1)$ & $1(1)$ & $2(1)$ & $2(1)$ \\
\hline A & Rubus275a & $116 / 126$ & $131 / 184$ & $116 / 146$ & $129 / 131$ & $142 / 178$ & $150 / 184$ & 106-192 & $4(4)$ & $12(6)$ & $10(4)$ & $2(1)$ & $2(1)$ & $2(1)$ & $2(1)$ & $2(1)$ \\
\hline B & RhM003 & $196 / 198$ & $196 / 200$ & $198 / 204$ & $196 / 214$ & $196 / 214$ & $196 / 214$ & $188-216$ & $3(4)$ & $8(6)$ & $7(4)$ & $2(1)$ & $2(1)$ & $2(1)$ & $2(1)$ & $1(1)$ \\
\hline B & RhM011 & $277 / 316$ & $282 / 286$ & $280 / 288$ & $282 / 284$ & $282 / 284$ & $278 / 286$ & $248-314$ & $4(4)$ & $14(6)$ & $10(4)$ & $2(1)$ & $2(1)$ & $2(1)$ & $1(1)$ & $2(1)$ \\
\hline B & RiM019 & $185 / 220$ & $167 / 181$ & $183 / 185$ & $183 / 192$ & $181 / 185$ & $169 / 185$ & $167-220$ & $3(2)$ & $6(3)$ & $5(4)$ & $2(1)$ & - & - & $2(1)$ & $2(1)$ \\
\hline B & Rubus285a & $175 / 183$ & $169 / 171$ & $169 / 177$ & $177 / 181$ & $177 / 193$ & $175 / 193$ & $160-243$ & $3(4)$ & $10(6)$ & $8(4)$ & $2(1)$ & $2(1)$ & $1(1)$ & $1(1)$ & $2(1)$ \\
\hline
\end{tabular}

* Number of alleles amplified (number of accessions successfully amplified); ${ }^{1}$ Black raspberry (Rubus occidentalis); four accessions tested; ${ }^{2} \mathrm{Blackberries} \mathrm{(Rubus} \mathrm{spp.);} \mathrm{six} \mathrm{accessions} \mathrm{tested;}$

${ }^{3}$ Hybrid berries (raspberry x blackberry); four accessions tested; ${ }^{4} R$. coreanus; one accession tested; ${ }^{5} R$. crataegifolius; one accession tested; ${ }^{6}$. odoratus; one accession tested; ${ }^{7} R$. spectabilis; one accession tested; ${ }^{8} R$. strigosus; one accession tested. 
Hestia') and some of its descendants. Group 'B' comprises the majority of primocane-fruiting material from various programmes, as well as some very early ripening floricane-fruiting genotypes from the EMR programme ('Malling Juno', 'Malling Minerva' and 'Valentina') as well as some other EMR genotypes e.g. 'Malling Leo'. On the other hand, 'Heritage', its yellow sport 'Kiwigold' and its seedling 'Polana' seem to be further removed from other primocane-fruiting germplasm. The relationships identified using SSRs in this investigation, although coherent with pedigree information, did not carried statistically significant bootstrap support, a phenomenon previously reported in studies using SSRs in other species [21]. However, it is important to note that the purpose of the study was cultivar discrimination rather than an inference of genetic relatedness, and in this respect, SSRs remain a powerful tool.

This genotyping set will prove useful for verifying trueness-to-type of clonally propagated material as well as for aiding germplasm collection management (e.g. detection of re-propagation errors, detection of synonyms). For the former use, direct comparison with reference DNA from the original clone is sufficient; plant breeders and propagators would do well to store reference samples when embarking on large scale propagation. For the later purpose, the inclusion of a range of DNA controls covering a wide spread of allele sizes is advisable to avoid errors due to small shifts in allele sizing between runs. When comparing data generated in different laboratories following diverse methodologies (e.g. coordinated germplasm-collection management or consortium genotyping efforts) much larger differences can be found in allele assignation and thus, reference samples must be included in each analysis to allow normalization of allele sizes. Control genotypes for fingerprinting have been designated for strawberry, apple, pear and cherry [11,24]. A reference set for red raspberry should include widely available cultivars such as 'Autumn Bliss', 'Glen Ample' and 'Tulameen'; cultivars extensively used in the breeding of modern cultivars (e.g. 'Heritage', 'Latham' and 'Malling Jewel') and perhaps, as in the case of the sets proposed for tree fruit crops, genotypes from closely related species that have contributed to modern cultivars (e.g. R. occidentalis and R. spectabilis). As identification errors can occur even in fully curated collections, control genotypes for a reference set should be centrally provided by a single reliable source such as the USDA National Clonal Germplasm Repository (Corvallis, Oregon, USA).

This study has optimised a reliable and cost-effective protocol for genotyping in $R$. idaeus that allows accurate fingerprinting of red raspberry cultivars and breeding lines. The SSR markers chosen are robust, spread throughout the raspberry genome, highly polymorphic and work consistently when multiplexed providing high quality data that can be used confidently by breeders, propagators and growers alike to document and/or verify genotype identity. Furthermore, provided common reference samples are agreed upon, it will enable comparisons between different germplasm collections facilitating the identification of possible 'rogues' and unwanted duplications.

Fresh raspberry production is a high-input business heavily reliant on high quality plant material of specific cultivars. Enormous financial losses can be incurred by breeders, propagators and growers alike when trueness-totype of germplasm is lost. By routinely deploying DNA fingerprinting technology at critical stages in the cultivar development and propagation processes, costly errors can be avoided; therefore we expect this reliable and costeffective fingerprinting tool to be valuable to the raspberry industry and researchers alike.

\section{References}

[1] FAOSTAT http://faostat.fao.org accessed 15 December 2009.

[2] BHS: Basic Horticultural Statistics for 2009 (Defra): https://statistics.defra.gov.uk/esg/publications/bhs/2009/Basic\%20Horticultural\%20 Statisitcs\%202009.pdf.

[3] E.T. Stafne, J.R. Clark, C.A. Weber, J. Graham and K.S. Lewers, Simple sequence repeat (SSR) markers for genetic mapping of Raspberry and Blackberry, Journal of the American Society for Horticultural Science 130 (2005), 722-728.

[4] C.A. Weber, Genetic diversity in black raspberry detected by RAPD markers, HortScience 38 (2003), 269-272.

[5] J.G. Parent and D. Page Identification of raspberry cultivars by nonradioactive DNA fingerprinting, HortScience 27 (1992), 1108-1110.

[6] L. Amsellem, J.L. Noyer, T. Le Bourgeois and M. Hossaert-McKey, Comparison of genetic diversity of the invasive weed Rubus alceifolius Poir. (Rosaceae) in its native range and in areas of introduction, using amplified fragment length polymorphism, Plant Systematics and Evolution 228 (2000), 171-179.

[7] S. Pereira-Lorenzo, A.M. Ramos-Cabrer and M.B. Díaz-Hernández, Evaluation of genetics identify and variation of local apple cultivars (Malus $\times$ domestica Borkh.) from Spain using microsatellite markers, Genetic Resources and Crop Evolution 54 (2007), 405-420.

[8] G.M. Volk, C.M. Richards, A.D. Henk, A. Reilley, N.V. Bassil and J.D. Postman, Diversity of wild Pyrus communis based on microsatellite analyses, Journal of the American Society for Horticultural Science 131 (2006), 408-417. 
[9] J.B. Clarke and K.R. Tobutt A standard set of accessions, microsatellites and genotypes for harmonising the fingerprinting of cherry collections for the ECPGR, Acta Horticulturae 814 (2009), 615-618.

[10] R. Testolin, T. Marrazzo, G. Cipriani, R. Quarta, I. Verde, M.T. Dettori, M. Pancaldi and S. Sansavini, Microsatellite DNA in peach (Prunus persica L. Batsch) and its use in fingerprinting and testing the genetic origin of cultivars, Genome 43 (2000), 512-520.

[11] C.L. Govan, D.W. Simpson, A.W. Johnson, K.R. Tobutt and D.J. Sargent, A reliable multiplexed microsatellite set for genotyping Fragaria and its use in a survey of $60 \mathrm{~F} . \times$ ananassa cultivars, Molecular Breeding 22 (2008), 649-661.

[12] J. Graham, K. Smith, M. Woodhead and J. Russell, Development and use of simple sequence repeat SSR markers in Rubus species, Mol Ecol Notes 2 (2002), 250-252.

[13] J. Graham, K. Smith, K. MacKenzie, L. Jorgenson, C.A. Hackett and W. Powell, The construction of a genetic linkage map of red raspberry (Rubus idaeus subsp idaeus) based on AFLPs, genomic-SSR and EST-SSR markers, Theoretical and Applied Genetics 109 (2004), $740-749$.

[14] J. Graham, K. Smith, I. Tierney, K. MacKenzie and C.A. Hacket, Mapping gene H controlling cane pubescence in raspberry and its association with resistance to cane botrytis and spur blight, rust and cane spot, Theoretical Applied Genetics 112 (2006), 818-831.

[15] M.S. Lopes, B. Maciel, D. Mendonca, F.S. Gil and A.D. Machado, Isolation and characterization of simple sequence repeat loci in Rubus hochstetterorum and their use in other species from the Rosaceae family, Molecular Ecology Notes 6 (2006), 750-752.

[16] N.R.F. Castillo, B.M. Reed, J. Graham, F. Fernández-Fernández and N.V. Bassil, Microsatellite markers for fingerprinting raspberries and blackberries, Journal of the American Society for Horticultural Science 135(3) (2010), 271-278.

[17] M. Woodhead, S. McCallum, K. Smith, L. Cardle, L. Mazzitelli and J. Graham, Identification, characterisation and mapping of simple sequence repeat (SSR) markers from raspberry root and bud ESTs, Molecular Breeding 22(4) (2008), 555-563.

[18] K. Lewers, C.A. Saski, B.J. Cuthbertson, D.C. Henry, M.E. Staton, D.E. Main, A.L. Dhanaraj, L.J. Rowland and J.P. Tomkins, A blackberry (Rubus L.) expressed sequence tag library for the development of simple sequence repeat markers, BMC Plant Biology $\mathbf{8}$ (2008), 69.

[19] K.M. Evans, F. Fernández-Fernández and C.L. Govan, Harmonising fingerprinting protocols to allow comparisons between germplasm collections - Pyrus, Acta Horticulturae 814 (2009), 103-106.

[20] A. Patocchi, F. Fernández-Fernández, K. Evans, D. Gobbin, F. Rezzonico, A. Boudichevskaia, F. Dunemann, M. Stankiewicz-Kosyl, F. Mathis-Jeanneteau, C.E. Durel, L. Gianfranceschi, F. Costa, C. Toller, V. Cova, D. Mott, M. Komjanc, E. Barbaro, L. Kodde, E. Rikkerink, C. Gessler and W.E. van de Weg, Development and test of 21 multiplex PCRs composed of SSRs spanning most of the apple genome, Tree Genetics and Genomes 5(1) (2009), 211-223.

[21] A. Marchese, K.R. Tobutt and T. Caruso, Molecular characterisation of Sicilian Prunus persica cultivars using microsatellites, The Journal of Horticultural Science and Biotechnology 80 (2005), 121-129.

[22] D.L. Swofford, PAUP* phylogenetic analysis using parsimony (*and other methods). Version 4. Sinauer Associates, Sunderland, 2003.

[23] R.D.M. Page, TREEVIEW: An application to display phylogenetic trees on personal computers, Computer Applications in the Biosciences 12 (1996), 357-358.

[24] K.R. Tobutt and K.M. Evans, ECPGR 2007: Fruit Network - Microsatellite Workshop,Bioversity Newsletter for Europe. Bioversity International, Rome, Italy NL34 (2007), 8. 